\title{
Developing a Safety Culture Based on the Culture of Safe Behavior at Work-A Challenge for Polish Companies
}

\author{
Sadłowska-Wrzesińska J* \\ Faculty of Engineering Management, Chair of Ergonomics and Quality Management, \\ Poznan University of Technology, Poland
}

*Corresponding author: Joanna Sadłowska-Wrzesińska, Faculty of Engineering Management, Chair of Ergonomics and Quality Management, Poznan University of Technology, Poland, Tel: 0048616653364; Email: joanna.sadlowska-wrzesinska@put.poznan.pl

\section{Research Article}

Volume 1 Issue 3

Received Date: December 01, 2017

Published Date: December 26, 2017

DOI: $10.23880 /$ eoij-16000128

\begin{abstract}
Safety culture is an attitude of the community towards risk, threats and security and the values that are considered important. A high safety culture is linked to the high value of human health and life, and keeping the boundary between the necessary risks that are inherent in life and development and the provision of safety and protection against threats.

More and more companies are recognizing that investing only in the safety of machinery and technical equipment at a certain level of organization development is already insufficient. Building a safety culture based on shaping safe behaviors is widely propagated, also in Poland. However, the new problem arises - the lack of consistency in the implementation of the operational objectives in the context of behavioral programs.
\end{abstract}

Keywords: Behavior-Based Safety; Safety Culture; Accidents at Work; Observations

\section{Introduction}

One of the methods of preventing accidents, which not only leads to avoiding a lot of costs of accidents, but primarily aims to improve the conditions and methods of work - is to observe the behavior of employees while they are doing their work. Safety based on observation of behavior, also known as BBS (behavior-based safety), enables measurement and modeling of behavior: both reinforcing safe behaviors and eliminating the barriers that block them. Over time, it becomes possible to eliminate inappropriate, risky behaviors and, as a result, reduce the number of accidents at work, as evidenced by numerous studies [1-6].
Any analysis of the causes of accidents should be preceded by the definition of nonconformities with accepted standards for people and their behavior, work environment, equipment and materials, tasks performed, management and work organization. The causes of the accident are any deficiencies and irregularities that directly or indirectly contributed to the occurrence of an accident, related to material (technical) factors, to the general organization of work in the company or to the organization of the workplace and to the employee. Every accident at work is the result of a number of causes, so the sum of the causes is usually greater than the total number of accidents. Analysis of the causes of accidents in Poland 


\section{Ergonomics International Journal}

indicates a high number of threats resulting from human behavior and from improper organization of work. In the companies audited by state inspection bodies, the most frequent irregularities are those related to weaknesses in the training in occupational health and safety and following the principles of safe work by employees. This is mainly due to the lack of knowledge of rules and regulations, neglecting the risk, and the lack of an established habit of using safe work methods. Incorrect behavior of the employee is the cause reported in more than $55 \%$ of recorded cases ${ }^{1}$. In particular, it should be stressed that despite the downward trend in the overall number of accidents at work, the employee's incorrect behavior is still the main cause of accidents in Poland (Table 1).

\begin{tabular}{|c|c|c|c|c|}
\hline $2007 r$. & $2008 \mathrm{r}$. & 2009r. & 2010r. & 2011r. \\
\hline $9917154,4 \%$ & $\begin{array}{c}104402 \\
55,6 \%\end{array}$ & $8705255,2 \%$ & $9420755,2 \%$ & $9722254,2 \%$ \\
\hline 2012r. & 2013r. & $2014 r$. & $2015 r$. & 2016r. \\
\hline $9100054 \%$ & $8826755,5 \%$ & $\begin{array}{c}88642 \\
59 \%\end{array}$ & $\begin{array}{l}87622 \\
59,2 \%\end{array}$ & $8788660,1 \%$ \\
\hline
\end{tabular}

Table 1: Number of accidents at work (in absolute numbers) and frequency of reporting incorrect behavior as the cause of accidents (in\%).

Source: Own work based on data from Central Statistical Office.

In the context of improving safety in companies, different methods of shaping the culture of work safety are more and more often discussed. The basis of the desired safety culture is the high value attributed to health and life $[1,7]$. The formation of such a culture in a company requires developing of pro-safe attitudes and values, with the participation of all members of the group. Leadership attitudes expressed by managers - personal interest and concern for the safety of employees are the basis for all preventive and corrective actions aimed at shaping / modeling safe behaviors.

Dangerous behaviors that lead to accidents are currently one of the most serious problems in Polish workplaces. Only an in-depth analysis of the causes of dangerous behavior will allow designing appropriate preventive measures. Unfortunately, in the course of annual health and safety analyzes, it was observed that in the companies that implemented the BBS, the frequency of observations of behavior has been decreasing with each passing year.

\section{Methodology}

Despite the fact that they have high standards of safety and health, companies that have been selected for the research are not observing their own behavior, though observation is one of the key elements in the safety policy of the surveyed companies.

Four international multinational corporations, having branches in Poland in Wielkopolska, participated in the pilot study. All the companies surveyed are manufacturing companies, representing the food and automotive industries. Manufacturing employees (operators) are the most important asset of these companies, as they are the majority of employees. High security standards are employed in these companies, moreover they have a BBS system implemented and functioning a minimum of 3 years and a maximum of 5 years (the upper bound of the system is set to minimize the role of intermediary variables in the data comparison process). One of the goals of the safety policy (common to all the surveyed companies) is to convince employees to participate in health and safety management and to encourage them to report any dangerous events and/or improper working conditions - in line with the idea of continuous improvement.

The methods selected for the research were qualitative analysis of documents, analysis of literature, observation of the work environment and unstructured interviews. 


\section{Ergonomics International Journal}

\begin{tabular}{|c|c|c|c|}
\hline \multicolumn{4}{|c|}{ Frequency of observation of behavior since implementation of BBS program* } \\
\hline & After a year & After two years & After three years \\
\hline Company 1. & $92 \%$ & $81 \%$ & $66 \%$ \\
\hline Company 2. & $99 \%$ & $58 \%$ & $53 \%$ \\
\hline Company 3. & $79 \%$ & $75 \%$ & $69 \%$ \\
\hline Company 4. & $97 \%$ & $90 \%$ & $62 \%$ \\
\hline
\end{tabular}

Table 2: Frequency of behavior within three years since implementation of BBS (in \%).

Source: Own work

*compared with the predefined plan

The analysis of companies' documents clearly showed a gradual decline in activity concerning the behavioral observation system. In each of the companies surveyed, there were favorable changes resulting from the implementation of the BBS (decrease in accidents number, increased interest in safety, improvement of the overall work safety climate), however this did not prevent companies from falling behind in their involvement in behavioral programs.

\section{Discussion and Conclusion}

Preliminary research - unstructured interviews with auditors - showed a general reluctance of employees to participate in BBS programs, and among managers decreased engagement in conducting behavioral observations. Engaging in the improvement of safety should be considered as the basis for motivational actions [5-7]. Among many motivational factors in the area of occupational safety and health, giving good example through supervision and management is perhaps the most important part of the motivation system. Every manager should influence the safety of the workplace by organizing risk prevention activities and by communicating to interact with awareness of employees. Giving a good example manifests itself through:

- Managers demonstrating the importance of safety,

- Putting safety goals first, in advance of production goals,

- Expressing the belief that accident-free work is a viable option,

- Striving for the conformity of decisions, evaluation and dealing with the accepted principles and preferences concerning safety,

- Incorporation of safety issues into production management.
In the companies surveyed, employees are reluctant to participate in the observation-they point to the emergence of stress during safety audits $[8,6]$. They also do not like to pay attention to other employees, even if they notice their incorrect behavior because they do not want to be considered "informers". Of course, most employees adjust to the prevailing principles and execute BBS tasks, but their approach to behavioral practice seems to be mechanical-without conscious, in-depth reflection.

The companies have already reached a certain level of safety culture that is currently being strengthened by improving the BBS system. This is due to the fact that observation of employees' behavior in the context of behavioral safety is implemented, carried out and analyzed, and weaknesses identified concern frequency of observation - which in turn leads to a reduction in their role in the overall safety policy.

It is necessary to leverage the strength of the companies emerging from application of behavioral approach, and ensure that the team of people trained in behavioral auditing methodologies, implemented them in practice. From the preliminary research on the material collected, it is clear that abandonment of observation was caused by insufficient commitment to work, time pressure, overlap of production and management responsibilities, and deficits in effective interpersonal communication.

The results of the research confirm the assumptions presented in the introduction, and concerning the importance of the role of the managerial staff in the implementation of behavioral audits. This is important to remember that building a safety culture is a multi-stage process and a sustainable change in employees' behavior can be achieved if the behavioral surveillance system is continually improved and implications properly communicated to employees (Figure 1). 

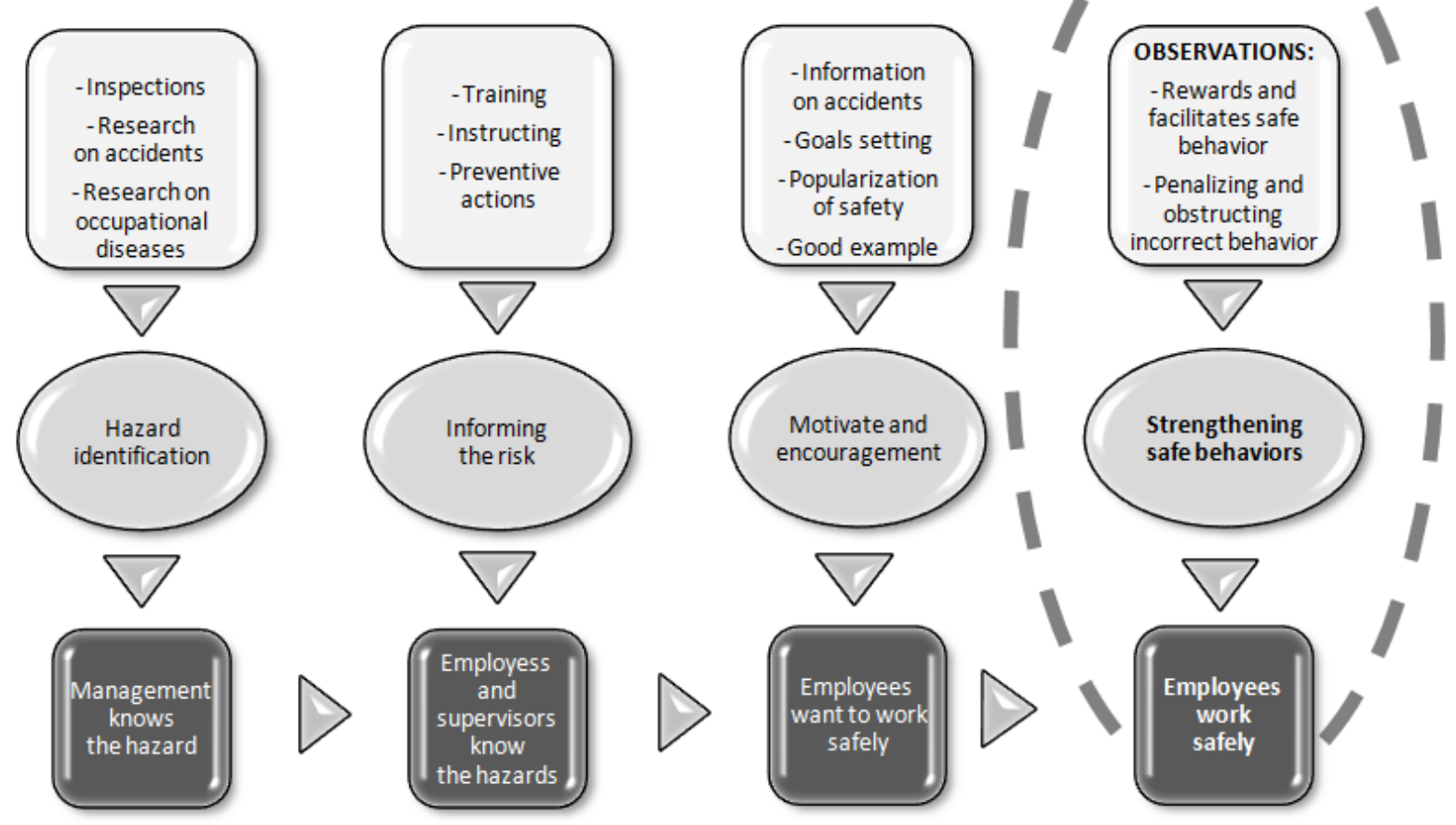

Figure 1: Towards safer behaviour - organizational-psychological approach.

Source: Own work

Managers play the key role and their attitude should be characterized by leadership capabilities and inspiring subordinates to change $[6,7,9]$. The research conducted was a pilot study aimed at finding the overall disadvantages of the observation system, with particular emphasis on the scale of omissions. The issues presented in the paper provide prospects for future research, and conclusions and recommendations - to design improvements to BBS processes.

\section{Conclusion \& Research Recommendations}

A more thorough analysis of the problem requires qualitative research and the appropriate preparation of employees to take part in these studies. The pilot study did not take into account, among other things, exogenous factors (as for example socio-political situation in the country, fluctuations in the economic level) that may affect the attitude of both employees and management toward behavioral security measures. Nevertheless, the analysis of errors in the implementation of behaviorbased programs can serve as an inspiration for organizations that will try to strengthen their safety culture based on trust and employee participation.

\section{References}

1. Gore FB (2002) Human Performance CognitiveBehavioral Modeling: A Benefit for Occupational Safety. Int J Occup Saf Ergon 8(3): 339351.

2. Grindle AC, Dickinson AM, Boettcher W (2000) Behavioral Safety Research in Manufacturing Settings: A Review of the Literature. Journal of Organizational Behavior Management 20(1): 29-68.

3. Hagge $M$, McGee $H$, Matthews $G$, Aberle $S$ (2017) Behavior-Based Safety in a Coal Mine: The Relationship between Observations, Participation, and Injuries over a 14-Year Period. Journal of Organizational Behavior Management 37(1): 107118.

4. Hermann JA, Ibarra GV, Hopkins BL (2010) A Safety Program That Integrated Behavior-Based Safety and 


\section{Ergonomics International Journal}

Traditional Safety Methods and Its Effects on Injury Rates of Manufacturing Workers. Journal of Organizational Behavior Management 30(1): 6-25.

5. Mościcka-Teske A, Sadłowska-Wrzesińska J, Butlewski M, Misztal A, Jacukowicz A (2017) Stressful work characteristics, health indicators and work behavior. The case of machine operators. Int J Occup Saf Ergon 23(4): 510-518.

6. Sadłowska-Wrzesińska J, Mościcka-Teske A, Stankowiak A (2016) Interpersonal and group communication in prevention of potentially hazardous accidents-the behavioral approach. In: Kiełtyka L, Jedrzejczak W, Kobis P (Eds.), Challenges of modern management. Creation of the intellectual capital of the organization, Scientific Society of Organization and Management, Warsaw, pp: 71-84.

7. Gabryelewicz I, Sadłowska-Wrzesińska J, Kowal E, Kowal A (2015) Safety climate level as a tool aiding safety management in a production facility. 6th International Conference on Applied Human Factors and Ergonomics (AHFE 2015) and the Affiliated Conferences, AHFE 2015, Elsevier 3(2015): 47244731.

8. Sadłowska-Wrzesińska J (2014) Analysis of psychosocial risk in the context of the objectives of macroergonomics. Advances in Social and Organizational Factors, Edited by Peter Vink, AHFE Conference 2014, pp: 277-285.

9. Kawecka-Endler A, Sadłowska-Wrzesińska J (2017) Negotiation in OHS routines-selected aspects. Occupational Safety and Hygiene SHO2017Proceedings Book. In: Arezez P, et al. (Eds.), Portuguese Society of Occupational Safety and Hygiene (SPOSHO), pp: 49-51. 